\begin{tabular}{|c|c|c|}
\hline $\begin{array}{l}\text { PUCRS } \\
\text { PUC. }\end{array}$ & $\begin{array}{l}\text { ESCOLA DE } \\
\text { HUMANIDADES }\end{array}$ & $\begin{array}{l}\text { Revista Digital do Programa de Pós-Graduação em Letras da PUCRS } \\
\text { Letrônica, Porto Alegre, v. 14, n. 1, p. 1-14, jan.-mar. } 2021 \\
\text { e-ISSN: 1984-4301 }\end{array}$ \\
\hline dttp://dx & $.0 r g / 10.15448 / 1984-4301.2021 .1 .38742$ & \\
\hline
\end{tabular}

SEÇÃO: ARTIGOS

\title{
Leitura e compreensão leitora sob as óticas da Psicolinguística e da Análise do Discurso: uma aproximação
}

Reading and reading comprehension viewed from the perspectives of Psycholinguistics and Discourse Analysis: an approximation

\section{Graziella Steigleder Gomes $^{1}$}

orcid.org/0000-0003-3043-6385 graziella.gomes@edu.pucrs.br

\section{Tamiris Machado}

Gonçalves ${ }^{2}$

orcid.org/0000-0003-2551-0309 mtamiris@gmail.com

Recebido em: 30/07/2020. Aprovado em: 28/09/2020. Publicado em: 10/08/2021.

\section{(c) (1)}

Artigo está licenciado sob forma de uma licença Creative Commons Atribuicãa 4.0 Internacional.
Resumo: Este artigo discorre sobre leitura e compreensão leitora, a partir de noções provindas da Psicolinguística e da Análise do Discurso. Nesse ato, objetivamos promover uma aproximação entre as áreas a fim de construir um olhar que pode ser aplicado ao entendimento da linguagem em uso, uma vez que a habilidade de ler, tomada em seu caráter polissêmico, presta-se à interpretação de variadas semioses. A partir da realização de uma revisão bibliográfica, apresentamos as perspectivas, no que tange à leitura e à compreensão, e as submetemos a um diálogo. Nesta discussão, foi possivel compreender que ambas as vertentes de estudo contemplam a relação autor-texto-leitor, orientando que a construção dos sentidos é um processo relacionado às práticas sociais.

Palavras-chave: Leitura. Compreensão leitora. Psicolinguística. Análise do Discurso

Abstract: This article discusses reading and reading comprehension, based on notions coming from Psycholinguistics and Discourse Analysis. In this act, we aim to promote an approximation between these areas in order to construct a vision that can be applied to the understanding of language in use, as the ability to read, taken in its polysemic fashion, lends itself to the interpretation of various semiosis. After conducting a bibliographic review, we present these perspectives and submit them to a dialogue. In this discussion, it was possible to understand that both strands of study contemplate the relations among author-text-reader, which indicates that the construction of meaning is a process related to social practices. Keywords: Reading. Reading comprehension. Psycholinguistics. Discourse Analysis.

\section{Introdução}

Leitura. Compreensão leitora. Esses são conceitos amplos, que vão se especificando no interior das teorias em que se localizam. Nosso objetivo no presente estudo teórico e reflexivo é estabelecer relações entre as noções de leitura e compreensão leitora nos âmbitos da Psicolinguística $(P L)$ e da Análise do Discurso (AD), a fim de marcar um paradigma teórico para analisar a linguagem em uso. Nossa hipótese é que essas são áreas capazes de dialogar em razão de entender que os sentidos são edificados em um todo, não sendo exclusivamente linguísticos. Desta feita, empreendemos uma breve revisão de literatura acerca do tema para traçar conclusões sobre essa aproximação. 
Para tanto, na área da $\mathrm{PL}$, respaldamo-nos em autores como Smith (1991; 1999), Solé (1998) e Giasson (2000); dentre os brasileiros, figuram Leffa (1996), Koch e Elias (2008), Kato (1990) e Pereira (2013). No que concerne à $A D$, contamos com Pêcheux (1997; 2008), Charaudeau e Maingueneau (2014) e Orlandi (1987, 2008), entre outros.

Como início da discussão, vejamos as diferentes concepções que socialmente circulam a respeito do termo leitura, principalmente em meio não acadêmico. Para isso, recorremos ao Dicionário Houaiss de Língua Portuguesa (2001), cujos itens são capazes de dar pistas dos usos sócio-historicamente fixados na língua, já que o dicionário pode ser entendido como um registro histórico e social dos usos mais frequentes. Para leitura, encontramos 13 entradas lexicais. Interessam-nos especialmente as seguintes:

3. ação de tomar conhecimento de um texto escrito, para se distrair ou informar.

7. (fig.) maneira de compreender, de interpretar um texto, uma mensagem, um acontecimento. Ex:: ler nas entrelinhas; os criticos realizaram uma leitura muito limitada do filme.

9. ato de decifrar qualquer notação. Ex.: ler a temperatura em um termômetro, ler uma partitura musical. (HOUAISS, 2001, p. 1739)

Vemos, a partir dessas acepções, que, para o senso comum, o termo leitura apresenta caráter polissêmico, podendo ser resumido em: ler significaria produzir sentidos sobre algo, já que "tomar conhecimento", "compreender", "interpretar" e "decifrar", também entendidas no senso comum, são ações de produção de sentido.

De modo geral, na vida, então, podemos ler textos escritos, gráficos, diagramas, notas musicais, pessoas, cenas etc. Ler, assim, é atribuir sentidos - não somente aos elementos linguísticos, mas também aos não linguísticos; não somente ao que lemos em senso estrito, mas também ao que ouvimos e vemos, sendo essa uma prática intrínseca e inerentemente humana. Entretanto, para o linguista - e a depender da área de atuação -, leitura toma contornos mais específicos, como veremos na sequência. Nesse sentido, compreensão leitora também ganha contornos específicos quando pertence à metalinguagem, não se relacionando ao simples entendimento da compreensão e daquilo que é lido.

No que diz respeito à organização deste texto, o artigo estrutura-se da seguinte maneira: ademais desta introdução, a seguir, passamos a buscar a definição de leitura ao lado de compreensão leitora, relativamente às áreas eleitas para estudo. Por fim, o leitor encontrará considerações acerca dos caminhos percorridos neste artigo.

\section{A perspectiva da PL}

De modo geral, podemos dizer que a Psicolinguística é a ciência da cognição da linguagem, que procura desvelar "as conexões entre a linguagem e a mente" (TRASK, 2004, p. 243). Atua, dessa forma, na intersecção entre a Psicologia Cognitiva e a Linguística. Apesar de ter sido esboçada já na Antiguidade com os estudos de Platão, que se debruçava sobre questões relativas à aquisição do conhecimento, começa a despontar enquanto ciência autônoma partir dos anos 1950, principalmente em razão das contribuições de Noam Chomsky e da dicotomia competência/desempenho por ele desenvolvida. Entre os principais interesses da Psicolinguística, encontram-se a aquisição da linguagem e os processamentos linguísticos, que podem envolver fatores como a produção e compreensão da fala e/ou leitura. Neste texto, focaremos na leitura.

Em um artigo muito popular entre os psicolinguistas, Goodman (1967) assevera ser a leitura um "jogo psicolinguístico de adivinhação", ao combinar pensamento e linguagem. Para Widdowson (1979), a leitura não se refere a uma reação ao texto, mas à interação entre escritor e leitor que o texto propicia. Solé (1998, p. 27), por sua vez, explica que "[...] a leitura pode ser considerada um processo constante de elaboração e verificação de previsões que levam à construção de uma interpretação". Nesses termos, segundo Oakhil, Cain e Elbro (2017), para obter êxito, o leitor necessita construir o que os autores chamam de modelo mental, que pode ser entendido como esquema. Para Robert Sternberg e Karin Sternberg (2017), esquemas têm por função organizar conhecimentos, relacionando de forma significativa conceitos que entre si resguardam algum tipo de afinidade ou similitude. 
Todas essas definições deixam ver que ler não é um processo mecânico nem exato, é uma ação que coloca em jogo nossa experiência plena como sujeito. Smith (1991) sustenta que a leitura não pode ser dissociada de fatores que vão do perceptivo ao social, passando pela cognição e aspectos linguísticos. Ou seja, somente podemos ter a leitura em conta se a relacionarmos com o aprendizado e o pensamento, de forma holistica.

Nas palavras de Baretta e Pereira (2019, p. 142): "Na concepção psicolinguística, a leitura é considerada uma prática de construção de sentidos e seu produto primário é a compreensão". Nessa perspectiva, o compreender entrelaça o que observamos do mundo que nos circunda ao que temos em nossas mentes, o que sabemos, o que desejamos e o que esperamos (SMITH, 1991).

$\mathrm{Na}$ base da compreensão, encontram-se as previsões, que são perguntas que lançamos ao mundo. A compreensão se daria, então, a partir do encontro de respostas relevantes para essas questões. Dessa forma, se não pudermos prever, ficaremos confusos; se nossas previsões falham, surpreendemo-nos; se não temos nada a respeito do que prever, podemos nos sentir inseguros, desinteressados ou entediados. Portanto, a partir da eliminação, por parte do leitor, de respostas improváveis às previsões que ele projeta, as quais ele submete à avaliação durante a leitura, escolhendo qual dentre as alternativas que previu parece ser a mais adequada, é que ocorre a compreensão leitora (SMITH, 1991).

As perguntas que lançamos quando da leitura de dado texto as fazemos geralmente sem ter noção metacognitiva, isto é, sem delas tomarmos consciência. Da mesma maneira obtemos as respostas, criando sentidos para a leitura e para a compreensão, de forma mais abrangente. Focalizando o processo de modo consciente, uma importante habilidade para o leitor é saber que tipo de questionamentos fazer a partir de cada tipo de texto que encontra, pois, sem engendrar perguntas adequadas, a leitura sofrerá uma disrupção, ainda que o leitor se concentre ao máximo (SMITH, 1999).

É assim que, para Smith (1999), gerar previsões e testá-las não é uma idiossincrasia da leitura, é na verdade a forma como podemos compreender o mundo ao nosso redor, no qual a previsão desempenha papel crucial. Isso porque a habilidade de prever não é aprendida, é antes uma "maneira natural de encontrar sentido" (SMITH, 1999, p. 72, grifo do autor).

Há de se observar que diferentes leitores farão distintas perguntas - ainda que isso hipoteticamente pudesse ocorrer, caso fossem feitas as mesmas perguntas, as respostas não necessariamente seriam as mesmas. Assim sendo, levando-se em conta o mesmo texto e leitores diferentes - também o mesmo texto sendo lido pelo mesmo leitor, em momentos distintos -, estaremos diante de um novo texto, isto é, texto e leitor edificam sentidos em interação, de modo que não é possivel dissociar a leitura (e a escrita) dos processos cognitivos. Por esse motivo, Smith (1991) atenta para o fato de que, quando lemos, ativamos nossas emoções. Esse processo se organiza assim: no polo positivo, podemos ter sentimentos como interesse, curiosidade, encorajamento etc.; no polo oposto, ler pode ser um aborrecimento, algo que confunde e que gera ressentimento.

Portanto, conforme encontramos em Smith (1991), a leitura, do mesmo modo que outras categorias de pensamento, não pode ser dissociada de seus propósitos. Com efeito, Solé (1998, p. 22) afirma que "[...] sempre lemos para algo, para alcançar alguma finalidade", isto é, desde a leitura de uma bula de medicação ou da lista nutricional de um pacote de biscoitos até a leitura de um romance ou de uma notícia, sempre somos guiados por um objetivo: por fruição, para instrução sobre algo pontual, para alargar conhecimentos de mundo etc. Para tanto, concorrem conhecimento prévio e atitudes emotivas do leitor, bem como as especificidades do texto, que o constituem enquanto gênero, ou seja, enquanto grupos de textos que compartilham características, com funções sociais e discursivas em comum, já que gêneros textuais são maneiras pelas quais a lingua toma forma em um contexto sociocomunicativo particular (KENEDY, 2009).

De fato, frente a um texto, o leitor cria expectativas e é esperado que o escritor possa respondê- 
- las a partir das pistas linguísticas nessa materialidade. Esse processo é igualmente influenciado pela capacidade de processamento de leitura, isto é, conhecer o código, decodificá-lo, dar a ele sentido, compreendendo como se organiza, quais estruturas linguísticas apresenta a fim de com ele interagir, lançando sobre ele um ponto de vista.

Smith (1999) endossa o papel ativo do leitor na construção do significado, já que esse não recebe os conteúdos do texto passivamente, via convenções linguísticas. Justamente ao contrário, para isso conta com sua bagagem intelectual e experiência de vida.

Nesses termos, estariamos falando de um "leitor construtor-analisador" (KATO, 1990, p. 53). Assim, o leitor age como um "reconstrutor" do texto, deixando esse de ser considerado como apenas uma unidade formal, para também agregar um papel funcional - de comunicação:

Consistente com essa visão de texto é o modelo de leitura que a define como um ato de reprodução de processos de sua produção [...] [dando] conta [da] interação leitor-autor, dado a ela não se centrar no texto já estruturado, mas na simulação de sua construção. (KATO, 1990, p. 57)

Dessa percepção de sentidos que são edificados no texto, a depender de quem leia e do momento em que esse texto é lido, Koch e Elias (2011) falam em sentidos para o texto e não sentidos do texto, de modo a reforçar que essa é uma experiência complexa que depende de fatores textuais e extratextuais - como é o caso do repertório do leitor e das informações do gênero.

Entre os conhecimentos que concorrem para uma leitura fluente, encontra-se o conhecimento a respeito do gênero no qual determinado texto é concebido. Para Smith (1991), o reconhecimento dos esquemas relativos a gêneros serve como um leme que guia tanto o leitor quanto o escritor. O leitor, sendo familiarizado com determinado gênero, fará durante o ato de ler previsões que tenderão a ser confirmadas; igualmente, poderá passar a crer, baseado em sua cultura, que essas formas de dizer são "naturais, racionais e universais" (SMITH, 1991, p. 60), chegando ao ponto de considerar textos produzidos em outras condições, por um povo cujas práticas sociais são muito distantes das suas, uma "aberração" (SMITH, 1991, p. 60). Assim, para o autor, "todos tendemos a ser chovinistas acerca da linguagem à qual estamos mais intimamente conectados; nosso próprio idioma é 'natural', e o resto é 'estrangeiro, estranho'" (SMITH, 1991, p. 60).

Tendo isso em vista, a compreensão de dado texto será facilitada se estivermos familiarizados com o gênero ao qual esse pertence, pois, dessa maneira, mais poderemos antecipar e prever, com base em nosso conhecimento prévio: "Quanto mais um autor conhece e respeita as formas que o leitor irá prever, mais o texto será fácil de ler e recordar" (SMITH, 1991, p. 61). Ou seja, quando os escritores conhecem bem as peculiaridades sobre o gênero no qual estão produzindo seu texto, mais facilidade terão para lidar com as liberdades e restrições que o circunscrevem. Já em relação ao leitor, quanto mais familiaridade com o gênero que a ele se apresenta, mais é capaz de supor sobre o que lê, mais atos de predição realiza, mais reações é capaz de fazer entre as pistas linguísticas, o estilo e a estrutura do texto.

Smith (1991) chama estruturas do discurso às formas de interação entre falante-ouvinte, escritor-leitor. Ele explica que, na conversação, sabemos quando o falante terminou seu turno de fala e pode tomar a palavra, quando é possivel interromper ou não um fluxo de fala etc. $\mathrm{E}$ transpõe essas características da conversação face a face para a escrita:

Os leitores podem esperar que os escrito-
res observem as estruturas convencionais do
discurso, e os escritores podem esperar que
os leitores os compreendam. As estruturas
formam a base da previsão. A maneira onde
os capitulos e parágrafos estão organizados e
expostos nos livros é uma questão de estrutura
de discurso. (SMITH, 1991, p. 60)

Dessa maneira, ainda na perspectiva de Smith (1991, p. 61), as "estruturas são as bases para nossa compreensão dos textos. Se não conhecemos as estruturas relevantes, então não compreenderemos os textos, ou nossa leitura destes será distorcida". Assim, a estrutura diz dos modos de ler, daí a importância do contato com um amplo repertório de 
gêneros textuais, em razão de que a familiaridade com o gênero contribui para sua leitura.

Nesses termos, Smith (1999, p. 115) atenta para o fato de que pode ser complicado ler um texto com o qual o registro não estamos acostumados - "jargões diferentes, gírias, ou 'formas de falar'". Esses diferentes registros de linguagem implicam que os interlocutores possuam conhecimento do tópico, de seu assunto e também dos aspectos linguísticos, que permitem realizar o intercâmbio de informações, já que, mesmo um leitor fluente, se confrontado com textos com os quais não está acostumado, poderá apresentar dificuldades em processá-los.

A partir do exposto, vemos que as convenções da linguagem escrita são essenciais quando do momento de comunicação e consequente compreensão. Assim, a leitura pode ser vista, nessa perspectiva, também enquanto um acontecimento social, já que se vincula às experiências leitoras, à memória de gêneros, aos contatos com o escrito, a padrões e estruturas do universo do ler.

Relativamente a leitores experientes e inexperientes, Smith (1999) expõe que a vantagem que os primeiros têm em relação aos segundos reside não em habilidades que possam facilitar a compreensão, mas sim na familiaridade com um grande número de espécies de textos, que se torna, portanto, de extrema importância, pois, mesmo leitores competentes, se expostos a um gênero com o qual não têm familiaridade, podem ler como principiantes. O oposto pode ocorrer com leitores em nivel de aprendizes: relativamente a um gênero com o qual têm contato rotineiro, poderão apresentar leitura fluente, por reconhecimento dos aspectos gerais.

Nesses termos, podemos dizer que as relações de afinidade do leitor com o gênero são imprescindiveis para a leitura. Isso porque conhecer as caracteristicas do gênero é saber sua estrutura, é entender sua dinâmica e, mais ou menos, ter ideia de uma organização informacional, de disposição de ideias, de léxico, de possiveis construções de sentido, já que a organização da linguagem, sua escolha vocabular, estrutura sintática e disposição textual se edificam em razão do gênero.
Dando seguimento às diferentes concepções que a leitura pode assumir, Leffa (1996) discorre sobre duas noções restritas: a que advoga ser o ato de ler a extração de significado do texto e aquela na qual ler é atribuição de sentidos. Na primeira, temos o processo ascendente, ou bottom-up, no qual a direção da leitura vai do texto ao leitor; e na segunda, o processo descendente, ou top-down, em que a ênfase recai sobre o leitor em direção ao texto.

Olhando esses movimentos separadamente, Leffa (1996) considera a concepção de leitura enquanto extração de sentidos do texto problemática, fazendo uma analogia entre o texto e uma mina que o explorador esvazia por meio da mineração. Nesse sentido, afirma que no texto o "conteúdo não se transfere para o leitor, mas antes se reproduz no leitor, sem deixar de permanecer no texto" (LEFFA, 1996, p. 13). Não há extração; há relação.

A segunda concepção de leitura em sentido restrito que Leffa (1996) lista refere-se à atribuição de sentido ao texto. O foco passa então a ser não o texto, mas o leitor. Nesse caso, o texto, por um lado, pode apresentar lacunas que precisam ser preenchidas com o conhecimento prévio que o leitor traz consigo; ou, por outro lado, se o texto trouxer informações mais que as necessárias para a compreensão, tornam-se redundantes. Nesse caso, é preciso que filtremos os conteúdos que se sobrepõem para poder proficientemente processar o texto.

Para Leffa (1996), essa abordagem também apresenta problemas: ao dar ênfase ao papel do leitor, pode-se argumentar que qualquer interpretação, a partir de um mesmo texto, pode ser autorizada, o que não pode ocorrer, pois há limites para interpretações possiveis, já que a interpretação é validada à medida que se respalda na materialidade do texto, contemplando seus elementos linguisticos e extralinguísticos. Segundo o autor, ao ler um poema satírico e interpretá-lo literalmente, o leitor terá atribuido a esse texto um sentido; mas, ao não o relacionar à situação social em que esse se circunscreve, esse ato perde a validade, pois perde os laços que o ligam à sua realidade mais imediata. Nes- 
ses termos, não se pode falar em atribuição; há relação do leitor com o texto.

Pereira (2013) explica que os processos bottom-up e top-down são simultâneos, ocorrendo em relação. O bottom-up é a leitura minuciosa, isto é,

[...] um processo de análise e de síntese em que, após o reconhecimento da palavra escrita, vão sendo construidos os sentidos, gradativamente, de palavras, frases, orações, até a macroestrutura, graças ao cruzamento com as informações provindas do processamento top-down. (PEREIRA, 2013, p. 36)

Isso se dá justamente em razão de o processamento top-down deixar ver os conhecimentos do leitor, ou seja, o que ele tem armazenado em sua memória. Ainda para Pereira (2013), os conhecimentos prévios estão organizados em redes hierárquicas, os previamente citados esquemas cognitivos: "São tais representações armazenadas na memória de longo prazo que interagem com o que está escrito no texto, permitindo ao leitor preencher os vazios [...] e chegar à compreensão" (PEREIRA, 2013, p. 36). Nesses termos, não estamos contemplando uma percepção em detrimento da outra, mas as relacionando.

Para Leffa (1996), a alternativa conciliatória passa por relacionar ambos os movimentos: considera o papel do leitor e do texto, acrescentando a intencionalidade, que marca o encontro do leitor com o texto. Satisfeita essa condição, pode dar-se a leitura, que consiste em:

[...] um processo feito de múltiplos processos, que ocorrem tanto simultânea quanto sequencialmente. Esses processos incluem desde habilidades de baixo nivel, executadas de modo automático na leitura proficiente, até estratégias de alto nivel, executadas de modo consciente. (LEFFA, 1996, p. 17-18)

O autor faz, portanto, referência aos processos cognitivos e metacognitivos envolvidos na leitura. Nessa mesma seara, Solé (1998) adota a concepção de leitura enquanto um processo interativo leitor-texto, ressaltando que, para que esse processo seja bem-sucedido, há a necessidade de existir objetivos que guiem a leitura, uma vez que, sempre que lemos, o fazemos com alguma finalidade. A autora também chama a atenção para o fato de que individuos que abordam o mesmo texto, mas com finalidades distintas, depreenderão desse informações igualmente distintas, em razão de sua motivação inicial. Assim, temos a figura do leitor como construtor do sentido quando do ato da leitura:

\begin{abstract}
[O] significado que um texto escrito tem para o leitor não é uma tradução ou réplica do que o autor quis the dar, mas uma construção que envolve o texto, [e] os conhecimentos prévios do leitor que o aborda e seus objetivos. (SOLÉ, 1999, p. 22)

Isto é:

Para ler, é necessário dominar as habilidades de decodificação e aprender as distintas estratégias que levam à compreensão. Também se supõe que o leitor seja um processador ativo do texto, e que a leitura seja um processo constante de emissão e verificação de hipóteses que levam à construção da compreensão do texto e do controle dessa compreensão - de comprovação de que a compreensão realmente ocorre. (SOLÉ, 1998, p. 24)
\end{abstract}

Ler é compreender o texto justamente porque o leitor não extrai sentidos de um texto, não deduz ou reproduz seus significados; antes, os constrói a partir da estrutura-texto que tem diante de seus olhos. Entretanto, não é somente a participação ativa do leitor, que nesse ato emprega um importante esforço cognitivo, que garante uma bem-sucedida leitura. Também o texto intervém nesse processo, já que, para que a produção de sentidos ocorra, esse deve possuir "uma estrutura lógica, uma coerência no conteúdo e uma organização" (SOLÉ, 1998, p. 40) que contribuam para esse propósito.

Assim, se é necessário, por um lado, que o leitor tenha estratégias de leitura baseadas em um objetivo; por outro lado, o texto em si precisa ter sido edificado com um propósito, estar sob determinada estrutura, apresentando progressão e relação entre suas partes, estar organizado em um gênero, tecer-se com certa linguagem, organizar-se de maneira específica. Tudo isso deixa ver a intenção do autor e já vai dando pistas do que poderiamos chamar de modos de ler.

Sobre essa materialidade texto, criação de um autor, incide o leitor com sua bagagem intelectual: o que ele já sabe, o que faz parte de 
suas vivências, o que ele possui em termos de conhecimentos enciclopédicos etc., o que está armazenado em sua memória, tudo é determinante na atribuição de significados. Nessa dinâmica entre texto e leitor, Solé (1998) argumenta sobre o papel do autor, já que ele precisa construir uma imagem de leitor presumido, pois é a partir dessa que ele edifica o texto.

O autor está no texto, no produto final a que temos acesso na hora da leitura. Ele não é a fonte dos sentidos, mas o arquiteto das possibilidades, pelo menos daquelas que justificam o enquadramento dos modos de ler que repousam naquele gênero, naquela organização sintática, naquelas palavras escolhidas, nas combinações feitas, na quantidade de informação, enfim, nas escolhas que o autor teve de fazer para criar o texto. Assim, se se pode dizer que o leitor é motivado por um objetivo, o autor também o é quando pensa em expressar o que deseja sob essa ou aquela forma.

Solé (1998) discorre sobre o leitor presumido, dizendo que o caminho contrário também é possivel: visualizar um escritor pressuposto a partir do texto que se lê. Quanto ao papel do escritor, ela explica que é preciso que o escritor leve em conta que:

Pode haver diferentes leitores, com distinta motivação, expectativas e conhecimentos. Por isso [deve-se procurar] elaborar um texto que "chegue" a todos que o abordem, isto é, que possa ser compreendido e interpretado por seus potenciais leitores. (SOLÉ, 1998, p. 40)

Cada objetivo de leitura estará motivado por certos enquadramentos, já que de todo o texto o leitor enfoca-se em um ou outro ponto, construindo sua expedição desse texto, acionando conhecimentos que dialogam com esse recorte feito por ele. Da dinâmica motivada pelos objetivos de leitura, surge uma leitura pontual, com uma compreensão pontual - não qualquer uma, já que estará amarrada aos elementos daquele texto e às pistas linguísticas que nele são encontradas.

Giasson (2000) analisa a evolução pelas quais o conceito de compreensão leitora tem passado ao longo dos anos. Ela explica que, em uma concepção mais remota e tradicional, na qual o foco era o texto, o leitor não tinha espaço para realmente compreender. Era seu papel buscar sentido, extraindo do texto o seu conteúdo, que seria transposto para a mente do leitor. O leitor era, então, um passivo receptor de informações. Aliado a essa concepção de leitura estava o ensino de estratégias, tais como decodificação, encontrar a ideia principal do texto, interpretar o que o autor pretendia dizer etc.

Argumenta Giasson (2000) que esses procedimentos, no entanto, não garantiam a leitura fluente por parte dos aprendizes, já que, para que as estratégias façam sentido, devem ser inseridas em um contexto prático de leitura. Não se nega que ensinar habilidades seja importante e útil, mas é necessário haver integração entre elas e o momento de leitura: "Uma habilidade de leitura separada de seu contexto perderá uma grande parte de sua significação" (GIASSON, 2000, p. 18). A leitura deve, nesses termos, ser tomada em seu aspecto holístico, no qual concorrem essas habilidades para uma atividade efetiva de leitura frente àquela materialidade textual.

Ainda para Giasson (2000), o modelo de compreensão leitora atual e mais aceito é o que integra o leitor, o texto e o contexto; a tendência é encarar a compreensão como um processo interativo no qual estão mescladas as informações do texto, os conhecimentos prévios do leitor e suas intenções diante do texto. Para a autora, essa abordagem às vezes causa certo desconforto nos professores, porque as diversas compreensões que podem emergir desse processo escapam a reconhecida procura pela intenção do autor. No entanto, nem todas as interpretações podem ser validadas: "O que se passa, com efeito, é que o autor utiliza certas convenções que supõe serem conhecidas pelo leitor. Se essa suposição não se verificar, a mensagem do autor será evidentemente mal entendida" (GIASSON, 2000, p. 19).

Dentre os componentes que para Giasson (2000) integram a compreensão leitora, a variável texto é aquela que se refere à materialidade linguística em si, na qual se deve levar em conta três aspectos essenciais: a intenção do autor, a estrutura do texto e seu conteúdo. Nessa perspectiva, a intenção do autor é o que irá determi- 
nar estrutura e conteúdo: na estrutura, tem-se a organização do texto; em relação ao conteúdo, "lesse] remete para os conceitos, conhecimentos e vocabulário que o autor decidiu transmitir" (GIASSON, 2000, p. 22).

É nesse item que se pode ver a intenção do autor, noção à qual se atrela a questão do gênero literário (GIASSON, 2000). Assim, a intenção do autor pode ser, via texto, "persuadir, informar, distrair" (GIASSON, 2000, p. 36). Para melhor apreender a noção de intenção do autor, faz-se necessário classificar os textos, porque os leitores, frente a esses, apresentarão comportamentos distintos. "No entanto, é preciso reconhecer que ainda não existe uma classificação perfeita de tipos de texto" (GIASSON, 2000, p. 36). A autora lista mais dois itens relevantes dentro da variável texto, quais sejam: estrutura e conteúdo. Em suas palavras:

A estrutura diz respeito ao modo como as ideias se organizam num texto, enquanto que o conteúdo remete para o tema, para os conceitos apresentados no texto. A estrutura do texto está muito ligada a seu conteúdo. Com efeito, o autor escolherá uma estrutura de texto que convenha ao conteúdo que quer transmitir. (GIASSON, 2000, p. 36)

Temos igualmente a variável contexto. Essa não tem ligação direta com o texto per se, mas influi na compreensão ao passo que envolve "[...] o contexto psicológico (intenção de leitura, interesse pelo texto...), o contexto social (as intervenções dos professores, dos colegas...) e o contexto físico (o tempo disponivel, o barulho...)" (GIASSON, 2000, p. 22).

Sobre o contexto social, a autora se limita a elencar condições de produção da leitura - as intervenções dos professores e/ou dos colegas. Vemos que a autora refere-se ao contexto social de leitura relativamente ao ambiente escolar, não fazendo referência ao sujeito leitor enquanto dotado de pensamentos e ideias, que atravessam o próprio ato de conceber a linguagem, portanto, de ler; desconsidera-se igualmente o contexto social mais amplo, no qual estão incluidas perspectivas sócio-históricas às quais o leitor está submetido e que fazem parte da maneira como esse faz emergir sentidos quando do ato de ler. como a seguir teremos chance de ver.

Seguindo nesse modelo de compreensão leitora, a variável referente ao leitor é, para Giasson (2000), a mais complexa de todas, ao envolver processos e estruturas. Os processos referem-se às habilidades pelo leitor postas em atividade quando do ato da leitura. Dividem-se em: microprocessos, processos de elaboração, processo de integração, processos metacognitivos e macroprocessos, dizendo respeito "às habilidades necessárias para abordar o texto, ao desenrolar das atividades cognitivas durante a leitura" (GIASSON, 2000, p. 32).

Em relação às estruturas, dividem-se em cognitivas e afetivas. São tidas enquanto conhecimentos e atitudes do leitor, ou seja, o que o constitui enquanto indivíduo. As estruturas cognitivas dividem-se em conhecimentos sobre a língua e conhecimentos sobre o mundo. Os conhecimentos de língua envolvem conhecimentos fonológicos, sintáticos, semânticos e pragmáticos: "O conjunto desses conhecimentos sobre a língua oral permitirá ao jovem leitor levantar hipóteses, por um lado, sobre a relação entre oral e escrito e, por outro, sobre o sentido do texto" (GIASSON, 2000, p. 27).

Os conhecimentos sobre o mundo são a base que garantirá que o leitor possa efetivamente compreender o texto, abarcando as novas informações que nesse pode vir a encontrar, já que somente a partir do que já sabe esse novo conhecimento pode ser construido. As estruturas afetivas, por seu turno, "compreendem a atitude geral face à leitura e aos interesses desenvolvidos pelo leitor" (GIASSON, 2000, p. 31). Alguns elementos que surgem dessa atitude frente à leitura correspondem a caracteristicas pessoais do leitor, tais como "a capacidade de arriscar, a sua auto-imagem geral, a sua auto-imagem como leitor, o medo do insucesso" (GIASSON, 2000, p. 31). Portanto, as estruturas afetivas são tão essenciais para uma leitura bem-sucedida quanto as estruturas cognitivas.

Depois de arroladas as considerações sobre leitura e compreensão leitora no viés da PL, na seção que segue, passamos às considerações sob as lentes da AD. 


\section{Sob as lentes da AD}

A Análise do Discurso é uma linha de estudo de inspiração francesa, cuja perspectiva é a lingua em uso, em sua relação com a história, estando perpassada pelo sujeito e atravessada, portanto, pelo simbólico, porque, conforme Lacan (1999), o sujeito é sujeito do simbólico, a-sujeitado ao Outro, que o estrutura e o determina. Assim, ele está cindido pela linguagem e suas formas de representação.

Nesse sentido, os sujeitos se constituem na e pela linguagem, dado o constante ser/estar na relação com o outro, produzindo efeitos da lingua em discurso. Os sujeitos se inscrevem em determinados campos de saber que delimitam o que dizer e como dizer, de modo que o que é dito está atravessado justamente pelas condições especificas de cada campo, de cada formação ideológica, que "constituem o sujeito e sua posição sócio-histórica" (DAMIÃO; STÜBE, 2020, p. 33).

Charaudeau e Maingueneau (2014) explicam que, dentre as muitas perspectivas que podemos ter da AD, entendê-la como um espaço crítico e de problematização é uma definição possivel. Esse lugar de experimentação toma como objeto o discurso, na emergência do social, relacionando, de modo amplo, aportes teóricos da Linguística, da Psicanálise, Filosofia e da Sociologia. Assim, ler e compreender o mundo nessa perspectiva, conforme Foucault (1971), mobiliza entender a complexidade própria do discurso, sua ordem, suas formas de exclusão e delimitação, suas práticas e sistemas de coerção e os limites do seu controle.

Em uma perspectiva ancorada na AD, Mariani e Jobim (2016) pontuam que ler implica a necessidade de sermos proficientes em uma ampla gama de gêneros, já que no entendimento em questão a experiência de leitura está relacionada ao vivenciar do mundo, simbolizado nos mais diferentes usos de língua, materializados em variados gêneros, colocados em ação por sujeitos históricos.

$\mathrm{Na}$ atribuição de sentidos ao que lê, o sujeito deve ser capaz de saber argumentar de forma a defender e justificar que pontos de vista, para ele, emergiram de dado texto. A leitura crítica, então, surge das formas como significamos, sempre atreladas relativamente ao momento histórico em que vivemos (MARIANI; JOBIM, 2016). Essa leitura vai passar pela compreensão dos efeitos da língua no discurso, compondo relações entre espaço, sujeito e lingua para edificar efeitos de sentido possiveis nos limites de certos recortes, sempre a partir do simbólico. Para Branco (2019, p. 118), tomando como base a perspectiva de Pêcheux na França, e de Orlandi no Brasil, para a AD, "os sentidos são produzidos como efeitos na ordem do ideológico e em condições de produção históricas determinadas, constituindo-se formas materiais pelo modo como se inscrevem ou não e inscrevem sujeito, língua, espaço ou não".

Nesse diapasão, entende Pêcheux (2008, p. 53) que

[...] todo enunciado é intrinsecamente suscetivel de tornar-se outro, diferente de si mesmo, se deslocar discursivamente de seu sentido para derivar para um outro (a não ser que a proibição da interpretação própria ao logicamente estável se exerça sobre ele explicitamente). Todo enunciado, toda sequência de enunciadosé, pois, linguisticamente descritivel como uma série (léxico-sintaticamente determinada) de pontos de deriva possiveis, oferecendo lugar à interpretação.

Assim, na AD podemos dizer que o texto aparece como um mediador das relações que se dão não somente entre leitor-texto, mas igualmente entre a imagem que esse leitor projeta do autor do texto, de outros leitores, de outros textos etc., extrapolando a leitura que está focada no material gráfico impresso que tem em mãos, sendo essas relações sempre historicamente atravessadas (MARIANI; JOBIM, 2016). Há no texto sempre uma diversidade de vozes outras, em tensão, construindo discursividades, fazendo emergir sentidos.

Os gêneros estão circunscritos em uma determinada formação discursiva e seu discurso está, pois, perpassado pela relação sujeito-história- língua. Essa trama é moldada pelas condições de produção e pela relação que mantém com os já ditos. Isso porque, novamente, "[...] o sentido é uma relação determinada do sujeito - afetado pela língua - com a história" (ORLANDI, 2013, p. 47). Nesses termos, todo o dizer está edificado a partir de uma memória discursiva, ou seja, o saber discursivo que torna possivel o dizer, o saber que é base para o dizivel (ORLANDI, 2013). 
Pêcheux, em "Semântica e discurso: uma crítica à afirmação do óbvio" (1997), não menciona processos de leitura per se. No entanto, há nessa obra referência à figura do locutor, que pode ser abrangentemente interpretado enquanto escritor, dado que, ao tomar parte em práticas sociais, edifica-se enquanto sujeito do discurso. Nessas, figura como autor e responsável pelos seus atos e dizeres, é, em outras palavras, o "sujeito de enunciação" (PÊCHEUX, 1997, p. 214). Nessas condições, é necessário haver "uma espécie de cumplicidade entre o locutor e aquele a quem ele se dirige, como condição de existência de um sentido da frase" (PÊCHEUX, 1997, p. 114, grifo do autor). Assim, é sublinhado o fato de que

[...] o sentido de uma palavra, de uma expressão, de uma proposição etc., não existe "em si mesmo" [...], mas, ao contrário, é determinado pelas posições ideológicas que estão em jogo no processo socio-histórico no qual lessas] são produzidas (isto é, reproduzidas) (PÊCHEUX, 1997, p. 160, grifo do autor).

Nessa perspectiva, do texto não emerge um único sentido, porque a língua que o edifica não é transparente, um código direto a ser decifrado; os sentidos vão sendo construídos no processo de ler, considerando a formação do sujeito nas dinâmicas de prática social, que deixam ver a linguagem perpassada pela historicidade. Assim, ao invés de focar na "tradição linguística que prioriza o aspecto comunicativo da linguagem humana, para a Análise do Discurso, o processo de tomar a palavra conduz o sujeito, de modo inevitável, a se engajar em práticas sócio-históricas" (MARIANI; JOBIM, 2016, p. 45).

Orlandi (2008) explica que o termo leitura pode se desdobrar em diversas interpretações, dentre essas, a leitura como atribuição de sentidos. Assim, "diante de um exemplar de linguagem, de qualquer natureza, tem-se a possibilidade de leitura" (ORLANDI, 2008, p. 7). Leitura também significa "concepção, que pode ser ligada ao que comumente designamos leitura de mundo" (ORLANDI, 2008, p. 7. grifos da autora). Academicamente, pode ser "a construção de um aparato teórico e metodológico de aproximação de um texto" (ORLANDI, 2008, p. 7). Em sentido mais restritivo, a leitura em âmbito escolar é entendida como aquela que está vinculada à aprendizagem formal.

Para a AD, há já na escrita do texto a presença de um leitor virtual, projetado pelo autor (ORLANDI, 2008). Denomina-se esse procedimento formação imaginária: o autor pode ter o seu leitor em potencial enquanto, nas palavras da autora, "cúmplice ou adversário" (ORLANDI, 2008, p. 9), justamente porque o discurso é edificado sempre de uma condição de produção dada projetando também uma dada posição (PÊCHEUX, 1993). Apesar de a escrita do texto e sua leitura constituírem-se em momentos distintos, ao criar seu texto, o autor já tem o leitor incluido na sua obra; na leitura, leitor virtual e leitor real interagem. Assim, o texto é o lugar que ambos têm em comum e no qual o processo de interação, que é a leitura, ocorre (ORLANDI, 1987).

Por essa razão, a autora questiona o conceito de "legibilidade do texto" (ORLANDI, 2008, p. 8), que já é atravessado por um tipo de julgamento de valor; na verdade, aponta que, pessoalmente, vê que a questão da legibilidade pode ser percebida em "graus" (ORLANDI, 2008, p. 9), não em uma questão absoluta em que se contrapõem tudo ou nada, mas que tem relação com a história, no sentido abrangente do termo.

Dessa forma, a interação no processo de leitura passa pela necessária relação entre o leitor projetado e o leitor sujeito no mundo; é essa uma relação de confronto. Esse fato, em sua visão, já se constitui em uma crítica ao postulado que afirma ser a leitura uma simples relação texto-leitor. Nesse âmbito, a relação é entre sujeito-sujeito, leitor real e virtual, que se dá mediante o texto, mas sempre se considerando que essa mediação se dá via relações sócio-históricas, sem as quais o texto perde sua relevância: "Leitura e sentido, ou melhor, sujeitos e sentidos se constituem simultaneamente, num mesmo processo" (ORLANDI, 2008, p. 10). Nessa direção, importam as condições de produção do texto, pensando-se em diferentes modos de leitura, em diferentes contextos, com diferentes objetivos (ORLANDI, 2008).

Na intrincada rede que relaciona autor/leitor/texto, a autora chama a atenção para o fato de que esses termos, em relação, bloqueiam a possibilidade de: 
a) Um autor onipotente, cujas intenções controlassem todo o percurso de significação do texto;

b) A transparência do texto, que diria por si (e apenas uma) significação, e, ainda,

c) Um leitor onisciente, cuja capacidade de compreensão dominasse as múltiplas determinações de sentido que jogam emum processo de leitura. (ORLANDI, 2008, p. 11)

As condições de produção da leitura estão, dessa forma, indissoluvelmente ligadas na articulação do linguístico e do ideológico, em uma "relação de posições histórica e socialmente determinadas" (ORLANDI, 2008, p. 11). Em adição, "Podemos dizer que há relações de sentido que se estabelecem entre o que um texto diz e o que ele não diz, mas que poderia dizer, e entre o que ele diz e o que os outros dizem" (ORLANDI, 2008, p. 11). No seio social, nas mais variadas formações discursivas, há teias de efeitos que se constroem na tensão entre o que é dito e não dito, a partir dos apagamentos, silenciamentos, regularidades e emaranhados que a lingua permite tecer. Para compreendê-los, o olhar social e histórico se faz necessário para ler o mundo e entender o que delimita o discurso lido.

Para além de ser o terreno comum entre autor e leitor, o texto, tido enquanto uma "unidade complexa de significação" (ORLANDI, 1987, p. 180), não pode ser considerado uma unidade completa, pois é de cunho intervalar: seu sentido não reside em seu número de linhas, ou mesmo em seus leitores; ocorre, de modo especifico, no espaço discursivo que há entre os interlocutores. Do mesmo modo, não pode ser tomado enquanto segmentos dissociáveis, ao contrário: deve ser visto como um todo significativo. Ou seja: para Orlandi, há no texto uma característica "indefinivel", que surge do fato de que só é possivel apreendê-lo enquanto uma totalidade (ORLANDI, 1987, p. 180) - totalidade simbólica, compreendida no seio social e histórico.

Assim, a autora define dois momentos do texto: aquele do texto enquanto objeto teórico, não acabado, e enquanto objeto empírico, tomado por sua superfície linguística. Esse último pode de fato ter começo, meio e fim; ter, então, um acabamento. Interessa ao analista do discurso o texto enquanto objeto teórico: a $A D$ devolve ao texto enquanto produto estético a incompletude que lhe é inerente, restitui-lhe os sentidos que pode instaurar e leva em conta suas condições de produção. Dessa forma, a partir de diferentes concepções de texto, podemos ter diferentes concepções de leitura: pode tanto ser a mecânica aplicação de uma técnica ou pode revelar sentidos a partir da tensa relação que se dá entre seus interlocutores (ORLANDI, 1987).

O leitor e o texto resguardam relações que englobam a situação de enunciação e o contexto. Para Orlandi (1987), o contexto não deve ser visto como aparato linguístico, mas como contexto textual, enquanto uma unidade que organiza sua totalidade em distintas partes. Esses traços conferem à leitura unidade: sem a relação leitor-situação e o contexto, não há o distanciamento necessário para que o leitor possa processar a leitura ou, em outras palavras, "o leitor perde o acesso ao sentido" (ORLANDI, 1987, p. 185):

\begin{abstract}
De forma geral, podemos dizer que o sujeito da linguagem não é um sujeito-em-si, mas tal como existe socialmente e, além disso, a apropriação da linguagem é um ato social, isto é, não é o individuo enquanto tal que se apropria da linguagem uma vez que há uma forma social dessa apropriação. (ORLANDI, 1987, p. 188)
\end{abstract}

Uma vez que a leitura não é dada, mas produzida no espaço em que ocorre a interlocução, sempre permeada por acentos valorativos, as relações que se dão entre autor e leitor podem assumir tons diversos, que "pode[m] variar desde a maior harmonia até a maior incompatibilidade ideológica, o que vai constituir a compreensão do texto" (ORLANDI, 1987, p. 191).

De fato, em Orlandi (1987) temos que a leitura na perspectiva do discurso é uma produção, e não algo dado. Assim, deve ser considerada em seu aspecto social, uma noção que concilia a liberdade de expressão e composição do escritor com os aspectos da língua em si, materialidade por meio da qual o discurso pode ser proferido.

Há de se levar em conta as condições de produção do texto e as condições de produção de 
leitura, que envolvem aspectos como situação enunciativa e contexto sócio-histórico no qual a leitura emerge, o que, para autora, aponta para a relação do texto com sua exterioridade - ou seja, sua incompletude, que se refere à multiplicidade de sentidos que qualquer discurso pode fazer (ORLANDI, 1987) apenas sobre sua caracteristica intervalar, entendida como uma "margem de enunciados efetivamente realizados" (ORLANDI, 1987, p. 194), a autora afirma ainda que esse intervalo não é um vazio semântico, é antes um espaço determinado socialmente.

A incompletude do texto, dessa maneira, não é vista como lacunas que devem pelo leitor ser supridas:

O texto é incompleto porque o discurso instala o espaço da intersubjetividade, em que ele, texto, é tomado não enquanto fechado em si mesmo (produto finito), mas enquanto constituido pela relação de interação que, por sua vez, ele mesmo instala. (ORLANDI, 1989, p. 195)

Nesses termos, segundo Coracini (2001, p. 141), "ler pressupõe um sujeito que produz sentidos, envolvendo-se, dizendo-se, significando-se, identificando-se", criando relações sempre mediadas pela história e atravessadas pela ideologia. Assim, a $A D$ nos brinda com uma perspectiva de sentidos construídos sempre na relação eu-outro, perpassada pela história.

\section{Considerações finais}

No caminho percorrido no presente artigo, buscamos delinear uma possivel relação entre noções relativas à leitura e à compreensão leitora nos âmbitos da PL e da AD. Em uma via que concilia essas abordagens, podemos pensar que o foco não está no autor, cujo texto seria um depósito de suas experiências e que resta a quem lê identificar seus pensamentos e intenções. O foco tampouco recai sobre o texto, bastando ao sujeito, para decifrá-lo, meramente possuir o conhecimento do código linguístico, assim desempenhando um papel passivo de pura decodificação.

A compreensão só pode se dar mediante a interação entre as três instâncias envolvidas no ato de ler: autor-texto-leitor, levando-se em conta não somente aspectos cognitivos, mas igualmente sociais, já que, em boa medida, esse acontecimento é também determinado pelo contexto sócio-histórico no qual ocorre, concorrendo para isso as condições de produção do texto, bem como as condições de produção de leitura.

Na perspectiva da $A D$, o texto não é um amontoado de informações, que, devido a seu aspecto lacunar, devem ser preenchidas; a leitura é tida enquanto um processo interativo, um lugar para produção de sentidos.

A participação do leitor nesses processos se dá mediante suas competências linguísticas e cognitivas, estando as primeiras relacionadas ao conhecimento de língua e de gêneros. Relativamente à cognição, contribui para a compreensão do texto a memória, estratégias e habilidades de leitura mobilizadas, por exemplo, a capacidade de inferir.

Já o texto traz para o processo de compreensão leitora um tema, veiculado via língua e organizado em forma de gênero. Possui um propósito comunicativo e um leitor projetado, e é escrito sob determinadas circunstâncias e com propósitos definidos. Dai surge a compreensão, "Ique] deriva da interação entre essas instâncias (leitor e texto), estando inserida em uma situação na qual autor e leitor se encontram por meio do texto" (SPINILLO, 2013, p. 172-173).

Com efeito, a leitura, de forma geral, não ocorre sem um propósito: lemos com algum objetivo, seja ele mais pontual, como buscar em um pacote de biscoitos o número de calorias que esse alimento contém; seja lendo um memorando para fins de apresentação em uma reunião de trabalho, seja lendo um romance com vistas à fruição; dentre tantas outras formas que a leitura pode tomar. O que há de comum entre todos esses encontros que se dão entre textos e leitores diz respeito às condições extratextuais que se fazem presentes nesse ato: as condições de produção desse texto e as suas condições de produção de leitura.

Ler e compreender, como vimos, não se dão em um ambiente estéril, uma vez que, durante a leitura, o leitor vai ativando partes do conhecimento de mundo que já possui. Quanto mais 
o assunto do qual o texto trata seja familiar para ele, mais fluente será a leitura. Essa pode ser vista enquanto socialmente situada, não se assentando unicamente sobre aspectos de ordem linguistica que, evidentemente, são necessários para a decodificação do texto, mas que, isoladamente, não dão conta da compreensão.

Dado que cada leitor traz consigo vivências e saberes variados, é possivel que para diferentes leitores o texto produza sentidos igualmente distintos, implicando também nesse processo aspectos socioculturais, já que o meio social em que estamos inseridos pode agir como um filtro pelo qual vislumbramos as coisas do mundo, ou seja, agem sobre a forma como sentidos são construidos durante a leitura, vetando, assim, interpretações que extrapolem a materialidade discursiva e que não encontrem apoio no texto enquanto um todo significativo.

Podem igualmente ocorrer casos em que o mesmo texto lido pelo mesmo indivíduo em diferentes circunstâncias acarrete compreensões não contempladas na leitura inicial. Isso porque os objetivos de leitura podem ser diferentes ou porque as vivências que o leitor teve nesse interim modificaram seu conhecimento de mundo (ou mesmo enciclopédico) etc. Nessa condição, relativamente à leitura, é tarefa dos linguistas levar em conta "não somente os olhos, mas também os mecanismos da memória e da atenção, a ansiedade, a capacidade de correr riscos" (SMITH, 1999, p. 9) (entre outros). Para refletir sobre a compreensão leitora, nesses termos, é preciso considerar "a natureza e os usos da linguagem, [...] as relações interpessoais [e] as diferenças socioculturais" (SMITH, 1999, p. 9).

É dessa forma que

A leitura é o momento crítico da constituição do texto, pois é o momento privilegiado do processo da interação verbal: aquele em que os interlocutores, ao se identificarem como interlocutores, desencadeiam o processo de significação. Em outras palavras: é na sua interação que os interlocutores instauram o espaço da discursividade. Autor e leitor confrontados definem-se em suas condições de produção. Os fatores que constituem essas condições é que vão configurar o processo da leitura. (ORLANDI, 1989, p. 193, grifo da autora)
Em outras palavras: "Saber ler é saber o que um texto diz e o que ele não diz, mas o constitui significativamente" (ORLANDI, 2008, p. 11).

Operando nas convergências e relações que podem ser estabelecidas entre as abordagens acerca de leitura advindas da PL e da AD, podemos afirmar que saber ler ultrapassa o conhecimento do código escrito, configurando-se pelas práticas sociais nas quais o sujeito toma parte, nas formas como significa o mundo que o circunda. Por esse motivo, há a necessidade de fomentar o ensino e a aprendizagem da leitura sem os desvincular de seus aspectos socioculturais, das condições de produção do texto escrito e das condições de produção de leitura, reconhecendo o leitor enquanto um ser social, condição que se reveste de extrema relevância para seu sucesso enquanto leitor em formação.

Reconhecidas as especificidades de cada área, o diálogo entre as duas possibilita assumir um olhar teórico-metodológico para observar a linguagem em uso, edificada em torno de propósitos definidos, que visam a um leitor em potencial. Ambas nos oferecem metalinguagem para analisar a leitura e sua compreensão como uma relação entre texto e sujeito. Ambas fazem um sopesamento entre aspectos linguísticos e não linguísticos, indicando que a leitura - e sua compreensão - é um processo complexo para a realização do qual contribuem diferentes fatores.

\section{Referências}

BARETTA, Daniele; PEREIRA, Vera Wannmacher. Predição leitora e consciência textual: um estudo com alunos do ensino fundamental. Iha do Desterro. v. 72, n. 3, p. 139-173. Florianópolis, set/dez 2019. Disponivel em: https://Www.scielo.br/pdf/ides/v72n3/2175-8026-ides-72-03-139.pdf. Acesso em: 8 jun. 2020.

BRANCO, Luiza Kátia Castello. Relações discursivas entre espaço, sujeito e língua. In: SCHERER, Amanda et al. (org.). Efeitos da lingua em discurso. São Carlos: Pedro e João, 2019. p. 171-198.

CHARAUDEAU, Patrick; MAINGUENEAU, Dominique. Dicionário de Análise do Discurso. Coordenação e tradução: Fabiana Komesu. 3. ed. São Paulo: Contexto, 2014.

CORACINI, Maria José. Heterogeneidade e leitura na aula de lingua materna. In: CORACINI, Maria José: PEREIRA, Aracy Ernst. (org.). Discurso e Sociedade: Práticas em Análise do Discurso. Pelotas: EDUCAT, 2001. p. 137-154. 
DAMIÃO, Estela Aparecida; STÜBE, Angela Derlise. Sentidos sobre o indigena em livro didático de língua portuguesa. In: TFOUNI, Fábio Elias Verdiani; BERNARDO-SANTOS, Wilton James. Análise do Discurso e materiais de ensino. Aracaju: Criações, 2020. p. 31-50.

FOUCAULT, Michel. L'Ordre du discours, Leçon inaugurale ao Collège de France prononcée le 2 décembre 1970. Paris: Éditions Gallimard, 1971.

GIASSON, Jocelyne. A compreensão na leitura. Tradução de Maria José Farias. Portugal: ASA, 2000.

GOODMAN, Kenneth. S. Reading: a psycholinguistic guessing game. Journal of the Reading Specialist, v. 6 , p. 126-135, 1967. Disponivel em: https://www.csie.ntu. edu.tw/ r99922026/tmp_zero/Reading_A_Psycholinguistic_Guessing_Game.pdf. Acesso em: 12 out. 2020.

HOUAISS, Antônio. Dicionário Houaiss da lingua portuguesa. Rio de Janeiro: Objetiva, 2001.

KATO, Mary. O aprendizado da leitura. 3. ed. São Paulo: Martins Fontes, 1990.

KENEDY, Eduardo. Gêneros textuais e psicolingüistica: caminhos para um diálogo. In: ARANHA, Simone; PEREIRA, Tânia; ALMEIDA, Maria de Lourdes. (org.). Gêneros textuais e linguagem: diálogos abertos. João Pessoa: Ed. Universitária da UFPB, 2009. p. 21-33.

$\mathrm{KOCH}$, Ingedore Villaça; ELIAS, Vanda Maria. Ler e compreender: os sentidos do texto. São Paulo: Contexto, 2008.

LACAN, Jacques. Escritos. Rio de Janeiro: Zahar, 1999.

LEFFA, Vilson J. Aspectos da leitura. Porto Alegre: Sagra Luzzatto, 1996.

MARIANI, Bethania; JOBIM, José Luis. A leitura em perspectiva. In: RÖSING, Tania; ZILBERMANN, Regina (org.). Leitura: história e ensino. 1. ed. Porto Alegre: Edelbra, 2016. p. 35-47.

OAKHILL, Jane; CAIN, Kate; ELBRO, Carsten. Compreensão de leitura: teoria e prática. Tradução e adaptação de Adail Sobral. São Paulo: Hogrefe CETEPP, 2017.

ORLANDI, Eni P. A linguagem e seu funcionamento: as formas do discurso. 2. ed. Campinas: Pontes, 1987.

ORLANDI, Eni P. Discurso e leitura. 8. ed. São Paulo: Cortez, 2008.

ORLANDI, Eni P. Análise do Discurso: principios e procedimentos. 11. ed. Campinas: Pontes, 2013.

PÊCHEUX, Michel. Análise automática do discurso. Tradução de Eni Orlandi. In: GADET, Françoise; HAK, Tony (org.). Por uma análise automática do discurso: uma introdução à obra de Michel Pêcheux. 2. ed. Campinas: Unicamp, 1993. p. 61-161.

PÊCHEUX, Michel. Semântica e discurso: uma critica à afirmação do óbvio. Tradução de Eni P. Orlandi et al. Campinas: Editora da UNICAMP, 1997.

PÊCHEUX, Michel. O discurso: estrutura ou acontecimento. 5. ed. Campinas: Pontes, 2008.
PEREIRA, Vera Wannmacher. Compreensão da leitura e consciência textual nos anos iniciais. Revista Signo, Santa Cruz do Sul, v. 38, p. 29-43, 2013. DOI: http://dx. doi. org/10.17058/signo.v38io.4554. Acesso em: 28 jun. 2020.

SMITH, Frank. Compreendendo a leitura: uma análise psicolingüística da leitura e do aprender a ler. 3. ed. Tradução de Daise Batista. Porto Alegre: Artes Médicas, 1991.

SMITH, Frank. Leitura significativa. Tradução de Beatriz Affonso Neves. Porto Alegre: Artmed, 1999.

SOLÉ, Isabel. Estratégias de leitura. Tradução de Cláudia Schilling. 6. ed. Porto Alegre: Artmed, 1998.

SPINILLO, Alina Galvão. A dimensão social, lingüistica e cognitiva da compreensão de textos: considerações teóricas e aplicadas. In: MOTA, Márcia Peruzzi E. da; SPINILLO, Alina (org.). Compreensão de textos. São Paulo: Casa do Psicólogo, 2013. p. 171-198.

STERNBERG, Robert J.; STERNBERG, Karin. Psicologia cognitiva. 2. ed. São Paulo: Cengage Learning, 2017.

TRASK, Robert Lawrence. Dicionário de Linguagem e Linguistica. Tradução de Rodolfo Ilari. Revisão técnica de Ingedore Villaça Koch e Thaïs Cristófaro Silva. São Paulo: Contexto, 2004

WIDDOWSON, Henry George. Explorations in Applied Linguistics. Oxford: Oxford University Press, 1979.

\section{Graziella Steigleder Gomes}

Mestra em Letras, pela Pontificia Universidade Católica do Rio Grande do Sul (PUCRS). Atualmente, realiza doutorado no Programa de Pós-Graduação em Letras na PUCRS. É bolsista CAPES/PROEX.

\section{Tamiris Machado Gonçalves}

Doutora em Letras, pela Pontificia Universidade Católica do Rio Grande do Sul (PUCRS). Atualmente, realiza pós-doutoramento no Programa de Pós-Graduação em Estudos Linguísticos da Universidade Federal da Fronteira Sul (UFFS). É bolsista PNPD/CAPES.

\section{Endereço para correspondência}

Tamiris Machado Gonçalves

Universidade Federal da Fronteira Sul - Campus Chapecó Fronteiras Laboratório de Estudos do Discurso

Bloco A, sala 404

Rodovia SC 484 - km 02

89815-899

Chapecó, SC, Brasil. 